\title{
Measurements and Correlations of Liquid-liquid-Equilibria of the Mixtures Consisting of Ethanol, Water, Pentane, Hexane, and Cyclohexane
}

\author{
Chih-yung Huang ${ }^{1}$, Pey-yu Chung ${ }^{1}$, I-Min Tseng ${ }^{2}$ and Liang-sun Lee Le $^{1, *}$ \\ ${ }^{1}$ Department of Chemical and Materials Engineering, National Central University, Chung-li 32001, Taiwan \\ ${ }^{2}$ Material and Chemical Research Laboratories, Industrial Technology Research Institute, Hsinchu 30011, Taiwan
}

\begin{abstract}
In this study, the liquid-liquid equilibria of the mixtures consisted of ethanol, water, and the main components of gasoline fuel: pentane, hexane, and cyclohexane were experimentally determined. This study is related to the phase behavior when water in atmosphere is absorbed into ethanol + gasoline fuel (gasohol) and then possibly separates into two liquid phases in an automobile fuel tank or an underground storage tank. The liquid-liquid equilibria in this study include three ternary systems: ethanol + water + pentane, ethanol + water + hexane, and ethanol + water + cyclohexane; three quaternary systems: ethanol + water + pentane + hexane, ethanol + water + pentane + cyclohexane, and ethanol + water + hexane + cyclohexane; one quinary system: ethanol + water + pentane + hexane + cyclohexane. The present experiments were conducted at $293.15,303.15$, and $308.15 \mathrm{~K}$, and the experimental data were collected and some were compared to that available in literature, and finally all data were correlated with the UNIQUAC activity coefficient model.
\end{abstract}

Keywords: Liquid-liquid equilibrium, water, ethanol, hexane, pentane, cyclohexane.

\section{INTRODUCTION}

In order to reduce the green house effect partly caused by burning fossil fuel in transportation vehicles, the gasoline fuel has been blended with pure ethanol produced from bioresource to form the ethanol-gasoline fuel (abbreviated as gasohol) and has been practiced for decades. The gasohol has been successfully used in vehicles in many countries for environmental considerations for decades, particularly in Brazil. The roles, also the advantages, of ethanol in gasohol are: it is one of the constituent components of fuel for vehicle power and is also an additive replacing MTBE or other octane number enhancements which have been prohibited by environment protection regulations. But, a disadvantage of gasohol is that ethanol will absorb moisture from air and possibly causes phase separation of gasohol if water content is beyond a tolerance. And it is obvious that the phase separation could result in a loss of ethanol being used as a power fuel when it is drawn into the aqueous phase. Thus, it is worth studying the phase behavior of the mixture of ethanol, water, and gasoline. Gasoline is not a single component fuel since it contains more than 53 different hydrocarbon compounds. It is impractical and impossible to accomplish the phase study of such multi-component mixture. However, the composition analysis of petroleum gasoline shows that pentane, isopentane, hexane, 2-methylpentane, 3-methylpentane, and cyclohexane as given in Table $\mathbf{1}$ by the Taiwan CPC, are the major components. Thus, the study of phase equilibria of the mixture of water, ethanol, and the above major components may be a way to give the preliminary

*Address correspondence to this author at the Department of Chemical and Materials Engineering, National Central University, Chung-li 32001, Taiwan; Tel: +886-3-422-7151-34208; Fax: 886-3-425-2296;

E-mail: t3100206@ncu.edu.tw qualitative observation of phase behavior of gasohol and water mixture. In literature, few experimental data of liquidliquid-equilibrium (LLE) of these compounds have been reported. In 1992, the LLE data of ethanol, water, and pentane were reported by Galan, Cayero, and Aguilar [1] for the application to azeotropic distillation process. In 1996 and 2006, the LLE data and correlation of ethanol, water, and hexane mixture were published respectively by Tang and Liu [2] and $\mathrm{Xu}, \mathrm{Ju}$, Wang, and Huang [3]. Ross and Patterson [4] reported the LLE data for the mixture of ethanol, water, and $\mathrm{n}$-hexane, and that for ethanol, water, and benzene mixture for the study of surface and interfacial tension of these solutions. The LLE data of ethanol, water, and cyclohexane mixture have been reported by $\mathrm{Ju}, \mathrm{Xu}$, Shao, and Ying in 2006 [5]. In 2003 Gramajo de Doz, Bonatti, and Sólimo [6] reported the LLE data of ternary and quaternary of ethanol, water, cyclohexane, and benzene. In 2005, also Gramajo de Doz, Bonatti, and Sólimo [7] reported the LLE data of ethanol, water, benzene, cyclohexane, isooctane, and n-hexane and observed the very small water tolerance and that phase separation could result in a considerable loss of ethanol drawn into aqueous phase. Moriyoshi, Uosaki, Matsuura, and Nishimoto [8] studied the isothermal LLE of ethanol, water, and n-hexane from 0.1 to $200 \mathrm{MPa}$ at $298.15 \mathrm{~K}$. This isothermal investigation is different from the isobaric LLE that most researchers have performed.

As mentioned earlier, it is impractical and impossible to conduct experiments on the phase equilibrium of ethanol, water, and gasoline mixture. Thus, one way to solve this difficulty is obtaining the phase equilibrium data of mixtures which are qualitatively suitable to represent the original mixture. Table 1 reports there are seven components consisting of more than $85 \%$ in composition of a petroleum gasoline and can be considered as the major and important com- 
pounds. In addition, the consideration of physical configuration gives that among these compounds, n-hexane, 2methylpentane, and 3-methylpentane have very close molecular volume parameter and molecular area parameter, npentane and isopentane are in a different group of these two parameters, and methylcyclopentane and cyclohexane are in another group. It should also be mentioned that the molecular volume and molecular area parameters are two important parameters used for the UNIQUAC model for data correlation. Based on the above considerations and since the constituent components of gasoline are non-polar hydrocarbons, thus, these three compounds, pentane, hexane, and cyclohexane were selected to represent other major components for phase behavior study of mixtures with ethanol and water. This consideration would simplify very much the phase behavior study of the original ethanol, water, and gasoline mixture. Of course, we are aware of that the experimental data of the mixtures in this study cannot exactly agree to that of the original mixture, however, these data are still with thermodynamic significance and would give the preliminary qualitative behavior for understanding this mixture. The experiments of liquid-liquid equilibria conducted at different temperatures in this study include three ternary systems: ethanol + water + pentane, ethanol + water + hexane, and ethanol + water + cyclohexane; three quaternary systems: ethanol + water + pentane + hexane, ethanol + water + pentane + cyclohexane, and ethanol + water + hexane + cyclohexane; one quinary system: ethanol + water + pentane + hexane + cyclohexane.

\section{EXPERIMENTS}

\section{Chemicals}

The chemicals of ethanol, pentane, hexane, and cyclohexane are GR grade with purity higher than $99.0 \%$ and were purchased from the agent of Merck Co. (Germany) in Taiwan. All the chemicals were used without further purification. The deionized water (electric resistance, $18.2 \mathrm{MU} / \mathrm{cm}$ ) was generated from a Minipore distilled water generator.

\section{Experimental Apparatus and Procedure}

The experimental apparatus for the present LLE measurement, as shown in Fig. (1), is the one has been used for our previous studies given in the paper of Lee and Huang [9]. A glass cell of $60 \mathrm{~cm}^{3}$ in volume was immerged in a Neslab thermostat (Model RTE 221) with temperature was controlled to an uncertainty of $\pm 0.1 \mathrm{~K}$. The temperature of liquid in the cell was indicated by a thermometer (Amarell Co.) with an uncertainty of $\pm 0.1 \mathrm{~K}$.

Table 1. The Physical Properties of Seven Major Components in the Gasoline Product of Taiwan CPC Corporation

\begin{tabular}{|c|c|c|c|c|}
\hline Component & Mass \% & b.p. $\left({ }^{\circ} \mathrm{C}\right)$ & $\mathbf{r}$ & $\mathbf{q}$ \\
\hline n-hexane & 23.1639 & 69.0 & 4.998 & 3.856 \\
\hline n-pentane & 21.1063 & 36.1 & 3.825 & 3.316 \\
\hline i-pentane & 12.4926 & 28.0 & 3.825 & 3.312 \\
\hline 2-methylpentane & 10.8865 & 60.0 & 4.990 & 3.852 \\
\hline 3-methylpentane & 8.7603 & 63.3 & 4.990 & 3.852 \\
\hline methylcyclopentane & 5.7051 & 72.0 & 4.046 & 3.236 \\
\hline cyclohexane & 2.9426 & 81.0 & 4.046 & 3.240 \\
\hline others & 14.9427 & & & \\
\hline
\end{tabular}

$\mathrm{r}$ is the molecular volume parameter and $\mathrm{q}$ is the molecular area parameter of a pure component.

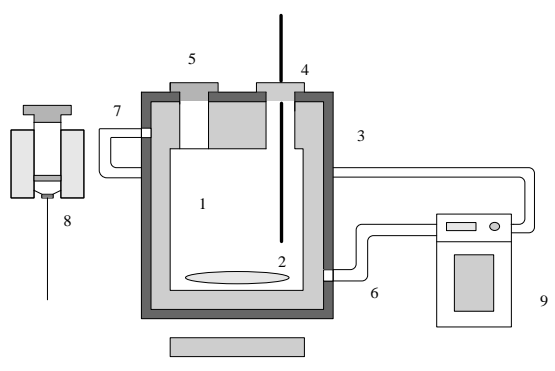

1. cell, 2.magnetic stirrer, 3.insulation, 4.thermometer, 5.septum,

6. entry of thermostated water, 7. exit of thermostated water,

8. thermostated syringe, 9. circulating thermostated cell

Fig. (1). Apparatus for liquid-liquid equilibrium experiments. 1. cell, 2. magnetic stirrer, 3. insulation, 4. thermometer, 5. septum, 6. entry of thermostated water, 7. exit of thermostated water, 8. thermostated syringe, 9. circulating thermostated cell. 
The LLE data for all mixtures were obtained as follow. Before each experiment, a sample of a specific composition of ternary, quaternary, or quinary mixture was prepared and then filled up the equilibrium cell which was placed in the thermostat. The mixture in cell was stirred for $2 \mathrm{~h}$ and left to settle for another $5 \mathrm{~h}$ to attain phase equilibrium. Each time, a sample of $0.5 \mu \mathrm{L}$ was withdrawn from cell with a syringe for composition analysis and the results were recorded. After finishing an experiment on a sample, the cell must be thoroughly washed, cleaned, and dried for next experiment. A gas chromatography (GC), a product (Model 9800) of Taiwan Gas Chromatography Co. with a TCD detector was used to analyze all samples. The GC column was a 80/100 Porapak Q, $2.0 \mathrm{~m} \times 1 / 8 \mathrm{in}$. The optimum GC operation conditions for the present study were: injection temperature, $200^{\circ} \mathrm{C}$; oven temperature, $210^{\circ} \mathrm{C}$; detector temperature $220^{\circ} \mathrm{C}$; detector current $80 \mathrm{~mA}$; and carrier gas, helium with a flow rate of $30 \mathrm{ml} / \mathrm{min}$. An experimental point was deter- mined by averaging three compositions of GC analysis with deviation less than $0.5 \%$ among four injections of a specific composition. In this study, the experimental data were reported with four digits after decimal point. This is the overall uncertainty estimated from the accuracies of measurements and GC analysis.

Before performing the experiments of this study, a test experiment was run on the LLE of ethanol + water + cyclohexane mixture to ensure the reliability of the apparatus and experimental skill. The results of this test experiment were compared to the literature data of Gramajo de Doz, Bonatti, and Sólimo [6]. Since there is no match between the present and literature data obtained at the same experimental conditions such that the exact comparison between the present and literature data can be made. Thus, Figs. 2 and 3 were drawn to show the good agreement of present experiment and literature data.

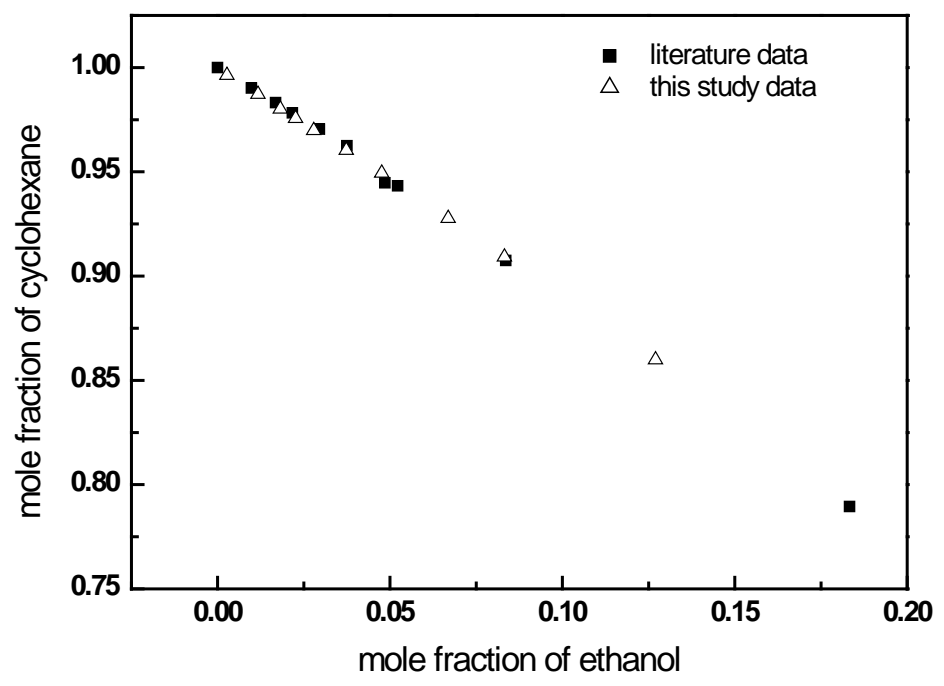

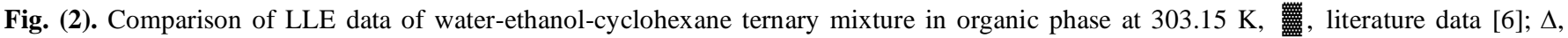
experimental data.

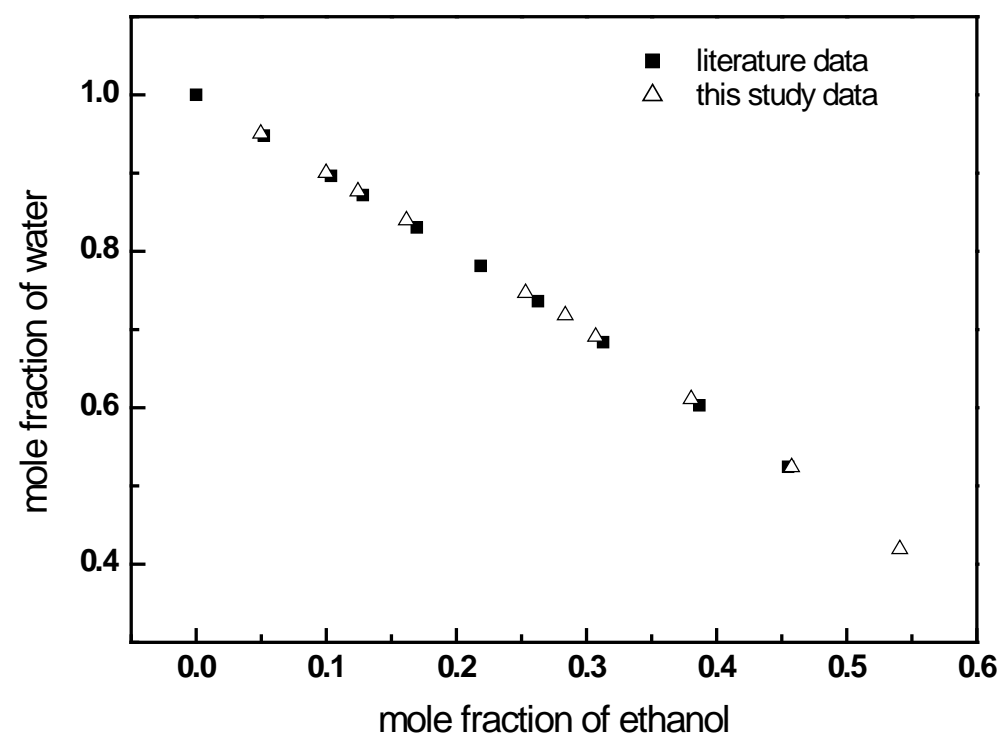

Fig. (3). Comparison of LLE data of water-ethanol-cyclohexane ternary mixture in aqueous phase at $303.15 \mathrm{~K}$, 䡒, literature data [6]; $\Delta$, experimental data. 


\section{THEORETICAL CONSIDERATION AND CORRE- LATIONS}

At liquid-liquid equilibrium of a mixture, the temperature, pressure, and the chemical potential of each constituent species throughout two liquid phases are equal and expressed as

$$
\mu_{i}^{\prime}=\mu_{i}^{\prime \prime} \quad i=1,2, \ldots n
$$

where $i$ stands for constituent component $i$ in the liquid mixture.

The thermodynamic relationship between the chemical potential and the liquid fugacity of species $i$ was expressed as

$$
d \mu_{i}=R T d \ln \hat{f}_{i}^{l} \quad i=1,2, \ldots n
$$

The above equation can be integrated from a standard state defined in the later paragraph and obtain

$\mu_{i}^{l}-\mu_{i}^{\theta}=R T \ln \left(x_{i} \gamma_{i}\right) \quad i=1,2, \ldots n$

Where $\mu_{i}^{o}$ is the standard state of species $i$. Thus, the chemical potentials of all species in the present study is represented by Eq. (3)

For the present study, the standard states of all components were chosen as the pure liquids at system temperature and pressure. Thus, the final equilibrium relation will be in the form

$$
\left(x_{i} \gamma_{i}\right)^{\prime}=\left(x_{i} \gamma_{i}\right)^{\prime \prime} \quad i=1,2, \ldots n
$$

For the correlations of experimental data, the models of NRTL and UNIQUAC were applied at the beginning. But the latter gave the better results than the former, thus, only the correlation results with the UNIQUAC model will be reported. Since the UNIQUAC model can be handily obtained from books and open literature, so it would not be repeated here. After the correlation model was determined, the experimental data were reduced by the maximum likelihood principle, which assumes that the experimental errors were random and independent and has the advantage of accounting for each concerned variable. The objective function for the present correlations of maximum likelihood principle is in the form of

$$
Q=\sum_{n=1}^{N D G} w_{n} \sum_{i=1}^{N P}\left[\sum_{j=1}^{N C-1}\left(\frac{x_{i, j}^{c a l}-x_{i, j}^{\exp }}{\sigma_{x, i, j}}\right)^{2}\right]
$$

Where $w_{n}$ is a weighing factor which was not considered for present systems and $\sigma_{x, i, j}$ is the standard deviation of composition measurements.

\section{EXPERIMENTAL AND CORRELATION RESULTS}

The LLE experiments of the ternary mixtures of ethanol + water + pentane, ethanol + water + hexane, and ethanol + water + cyclohexane were conducted at $293.15 \mathrm{~K}, 303.15 \mathrm{~K}$, and $308.15 \mathrm{~K}$ and the experimental data were reported in Tables 2 to 4. Since the phase diagrams of the LLE of a ternary mixture at three temperatures of $293.15 \mathrm{~K}, 303.15 \mathrm{~K}$, and $308.15 \mathrm{~K}$ are very similar, thus, only that at $303.15 \mathrm{~K}$ was given to depict the phase behavior of this mixture. With this consideration, Figs. 4, 5, and $\mathbf{7}$ were plotted for these three ternary mixtures all at $303.15 \mathrm{~K}$. Among the LLE data of these ternary mixtures, Figs. 2 and $\mathbf{3}$ are the plots of experimental data and literature data of Gramajo de Doz, Bonatti, and Sólimo [6] of ethanol + water + cyclohexane at 303.15 K already mentioned earlier. Fig. 8 is a phase behavior plot of this mixture at $308.15 \mathrm{~K}$ for the present experiment and literature data of $\mathrm{Ju}, \mathrm{Xu}$, Shao, and Ying [5]. In this figure, too many points cluster in a small region of cyclohexane rich corner and make it difficult to read, so that an enlargement of an encircled region was made and shows that the present data are more reliable since that of $\mathrm{Ju}, \mathrm{Xu}$, Shao, and Ying [5], denoted by empty circles, are not reasonably lying on the $\mathrm{C}_{6} \mathrm{H}_{12}-\mathrm{H}_{2} \mathrm{O}$ composition line. Fig. 6 compares the experimental and literature data of $\mathrm{Xu}, \mathrm{Ju}, \mathrm{Wang}$, and Huang [3] of ethanol + water + hexane mixtures. It shows the present data are more reliable than that of literature data since the latter are more scattering and inconsistent as shown in the encircled region. From tables and figures, one can observe that the solubility of water in organic components is very small such that phase separation will take place easily when water moisture in air is absorbed into gasohol and causes the loss of ethanol, which is a fuel for power, from organic phase into aqueous phase.

While doing the correlations of ternary mixtures, it was observed that all the pair interaction parameters determined directly from experimental data of ternary mixtures would not give better results than that determined from the binary mixtures. Thus, in this study, part of the pair interaction parameters are from literature and part were determined from present ternary experimental data if literature parameters are not available. In order to avoid too many tables in text, here, only the pair parameters of ternary mixture at $303.15 \mathrm{~K}$ are given in Table 5. The results of overall correlation of three ternary mixtures are listed in Table $\mathbf{6}$ showing the root mean square deviation (RMSD) of correlation results of each ternary mixture. Also, the correlation results were plotted along with the experimental data in Figs. 4 to 8. The good agreement between them is observable in theses figures.

The LLE experiments of quaternary mixtures were conducted for ethanol + water + pentane + hexane, ethanol + water + pentane + cyclohexane, and ethanol + water + hexane + cyclohexane at $293.15 \mathrm{~K}, 303.15 \mathrm{~K}$, and $308.15 \mathrm{~K}$. The experimental data were given in Tables 7 to 9. Although, no figures similar to ternary systems can be plotted for quaternary mixtures, however, these tables tell the similar behavior to the ternary mixtures of this study that the solubility of water in organic phase is also very small so that when moisture in air is absorbed into gasohol will easily cause phase separation and further transfer of ethanol from organic phase (used as fuel) to aqueous phase that is a process of losing useful fuel. The binary interaction parameters of the UNIQUAC model for these mixtures at $303.15 \mathrm{~K}$ were given in Table 10. The results of overall correlation of three quaternary mixtures were expressed in RMSD and listed in Table 11.

The LLE experiments of quinary mixture of ethanol + water + pentane + hexane + cyclohexane were conducted at $303.15 \mathrm{~K}$, and $308.15 \mathrm{~K}$ and the experimental data were listed in Table 12. 
Table 2. Experimental LLE Data of Ethanol (1) + Water (2) + Pentane (3) Ternary Mixtures

\begin{tabular}{|c|c|c|c|c|c|}
\hline \multicolumn{3}{|c|}{ Organic Phase } & \multicolumn{3}{|c|}{ Aqueous Phase } \\
\hline$x_{1}$ & $x_{2}$ & $x_{3}$ & $x_{1}$ & $x_{2}$ & $x_{3}$ \\
\hline \multicolumn{6}{|c|}{$293.15 \mathrm{~K}$} \\
\hline 0.0333 & 0.0018 & 0.9649 & 0.3186 & 0.6780 & 0.0034 \\
\hline 0.0447 & 0.0032 & 0.9521 & 0.3960 & 0.5941 & 0.0100 \\
\hline 0.0577 & 0.0042 & 0.9380 & 0.4590 & 0.5221 & 0.0189 \\
\hline 0.0697 & 0.0051 & 0.9252 & 0.5031 & 0.4674 & 0.0294 \\
\hline 0.0873 & 0.0076 & 0.9051 & 0.5539 & 0.3978 & 0.0483 \\
\hline 0.1047 & 0.0093 & 0.8861 & 0.5855 & 0.3466 & 0.0679 \\
\hline 0.1654 & 0.0156 & 0.8190 & 0.5986 & 0.3203 & 0.0811 \\
\hline 0.1510 & 0.0165 & 0.8325 & 0.6179 & 0.2653 & 0.1168 \\
\hline 0.2255 & 0.0292 & 0.7453 & 0.6104 & 0.1898 & 0.1998 \\
\hline 0.2416 & 0.0324 & 0.7260 & 0.6036 & 0.1785 & 0.2179 \\
\hline \multicolumn{6}{|c|}{$303.15 \mathrm{~K}$} \\
\hline 0.0339 & 0.0024 & 0.9637 & 0.2825 & 0.7151 & 0.0023 \\
\hline 0.0401 & 0.0033 & 0.9566 & 0.3170 & 0.6788 & 0.0042 \\
\hline 0.0536 & 0.0042 & 0.9421 & 0.3942 & 0.5945 & 0.0113 \\
\hline 0.0710 & 0.0057 & 0.9233 & 0.4629 & 0.5145 & 0.0226 \\
\hline 0.0827 & 0.0076 & 0.9098 & 0.4996 & 0.4722 & 0.0282 \\
\hline 0.1074 & 0.0108 & 0.8818 & 0.5521 & 0.3962 & 0.0518 \\
\hline 0.1376 & 0.0160 & 0.8463 & 0.5846 & 0.3361 & 0.0794 \\
\hline 0.2094 & 0.0294 & 0.7613 & 0.6067 & 0.2451 & 0.1482 \\
\hline 0.2614 & 0.0412 & 0.6973 & 0.6010 & 0.2079 & 0.1911 \\
\hline \multicolumn{6}{|c|}{$308.15 \mathrm{~K}$} \\
\hline 0.3032 & 0.0551 & 0.6417 & 0.5894 & 0.1967 & 0.2138 \\
\hline 0.2116 & 0.0336 & 0.7549 & 0.6007 & 0.2583 & 0.1410 \\
\hline 0.1382 & 0.0165 & 0.8454 & 0.5739 & 0.3451 & 0.0810 \\
\hline 0.1089 & 0.0118 & 0.8793 & 0.5399 & 0.4063 & 0.0538 \\
\hline 0.0881 & 0.0108 & 0.9011 & 0.4876 & 0.4811 & 0.0313 \\
\hline 0.0709 & 0.0104 & 0.9188 & 0.4297 & 0.5523 & 0.0180 \\
\hline 0.0517 & 0.0060 & 0.9424 & 0.3500 & 0.6429 & 0.0070 \\
\hline 0.0346 & 0.0031 & 0.9622 & 0.2547 & 0.7437 & 0.0016 \\
\hline 0.0235 & 0.0022 & 0.9743 & 0.1896 & 0.8100 & 0.0004 \\
\hline 0.0168 & 0.0018 & 0.9814 & 0.1495 & 0.8503 & 0.0001 \\
\hline
\end{tabular}


Table 3. Experimental LLE Data of Ethanol (1) + Water (2) + Hexane (3) Ternary Mixtures

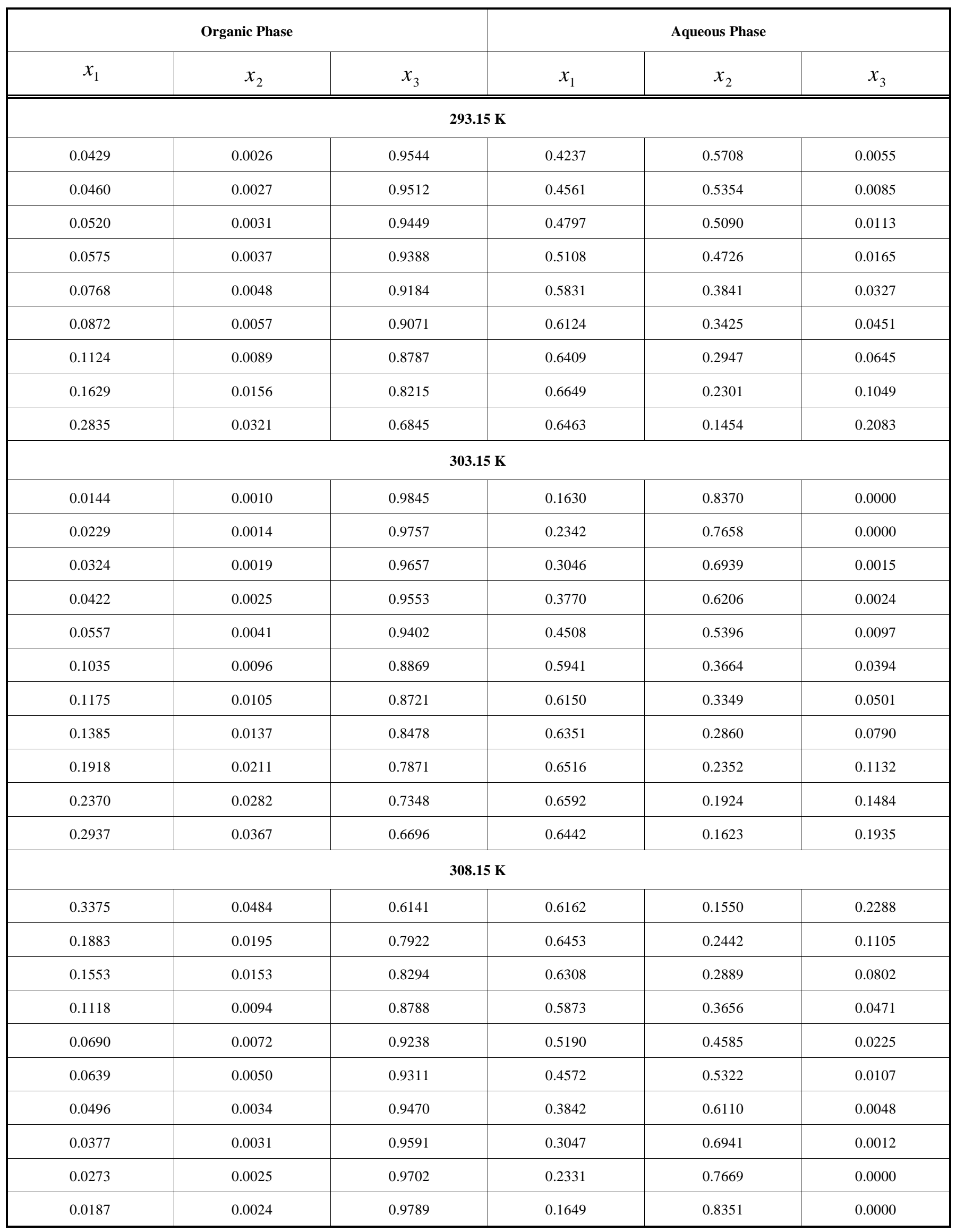


Table 4. Experimental LLE Data of Ethanol (1) + Water (2) + Cyclohexane (3) Ternary Mixtures

\begin{tabular}{|c|c|c|c|c|c|}
\hline$x_{1}$ & $x_{2}$ & $x_{3}$ & $x_{1}$ & $x_{2}$ & $x_{3}$ \\
\hline \multicolumn{6}{|c|}{ 293.15 K } \\
\hline 0.0131 & 0.0009 & 0.9859 & 0.2001 & 0.8002 & 0.0000 \\
\hline 0.0290 & 0.0020 & 0.9689 & 0.3735 & 0.6193 & 0.0073 \\
\hline 0.0333 & 0.0019 & 0.9648 & 0.4134 & 0.5748 & 0.0118 \\
\hline 0.0444 & 0.0028 & 0.9528 & 0.4969 & 0.4784 & 0.0247 \\
\hline 0.0998 & 0.0088 & 0.8914 & 0.6337 & 0.2621 & 0.1043 \\
\hline 0.1780 & 0.0174 & 0.8046 & 0.6348 & 0.1649 & 0.2004 \\
\hline \multicolumn{6}{|c|}{$303.15 \mathrm{~K}$} \\
\hline 0.0117 & 0.0011 & 0.9872 & 0.1615 & 0.8396 & 0.0000 \\
\hline 0.0182 & 0.0017 & 0.9801 & 0.2837 & 0.7182 & 0.0000 \\
\hline 0.0226 & 0.0018 & 0.9756 & 0.2531 & 0.7466 & 0.0003 \\
\hline 0.1270 & 0.0131 & 0.8599 & 0.6242 & 0.2614 & 0.1143 \\
\hline 0.2206 & 0.0273 & 0.7521 & 0.6217 & 0.1724 & 0.2058 \\
\hline \multicolumn{6}{|c|}{ 308.15 K } \\
\hline 0.2697 & 0.0409 & 0.6894 & 0.5915 & 0.1609 & 0.2476 \\
\hline 0.1453 & 0.0167 & 0.8380 & 0.6139 & 0.2575 & 0.1286 \\
\hline 0.0994 & 0.0097 & 0.8909 & 0.5845 & 0.3400 & 0.0755 \\
\hline 0.0776 & 0.0071 & 0.9153 & 0.5417 & 0.4101 & 0.0481 \\
\hline 0.0545 & 0.0042 & 0.9413 & 0.4587 & 0.5228 & 0.0185 \\
\hline 0.0428 & 0.0033 & 0.9539 & 0.3861 & 0.6040 & 0.0099 \\
\hline 0.0264 & 0.0025 & 0.9711 & 0.2554 & 0.7439 & 0.0007 \\
\hline 0.0153 & 0.0017 & 0.9830 & 0.1636 & 0.8364 & 0.0000 \\
\hline 0.0078 & 0.0014 & 0.9908 & 0.1003 & 0.8997 & 0.0000 \\
\hline 0.0035 & 0.0010 & 0.9954 & 0.0499 & 0.9501 & 0.0000 \\
\hline
\end{tabular}




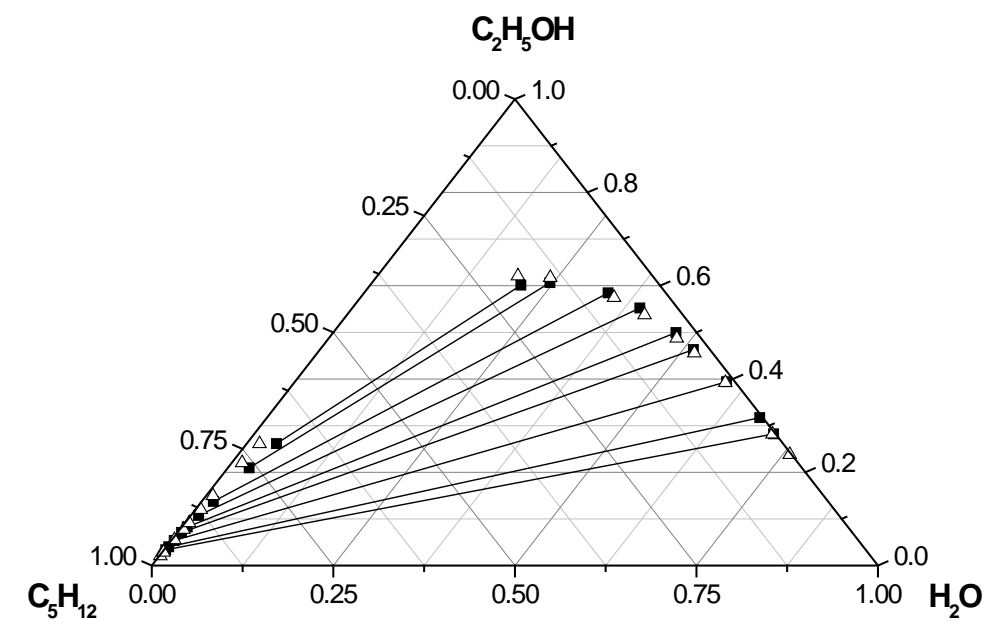

Fig. (4). LLE data of ethanol - water - pentane ternary mixture at $303.15 \mathrm{~K}$.

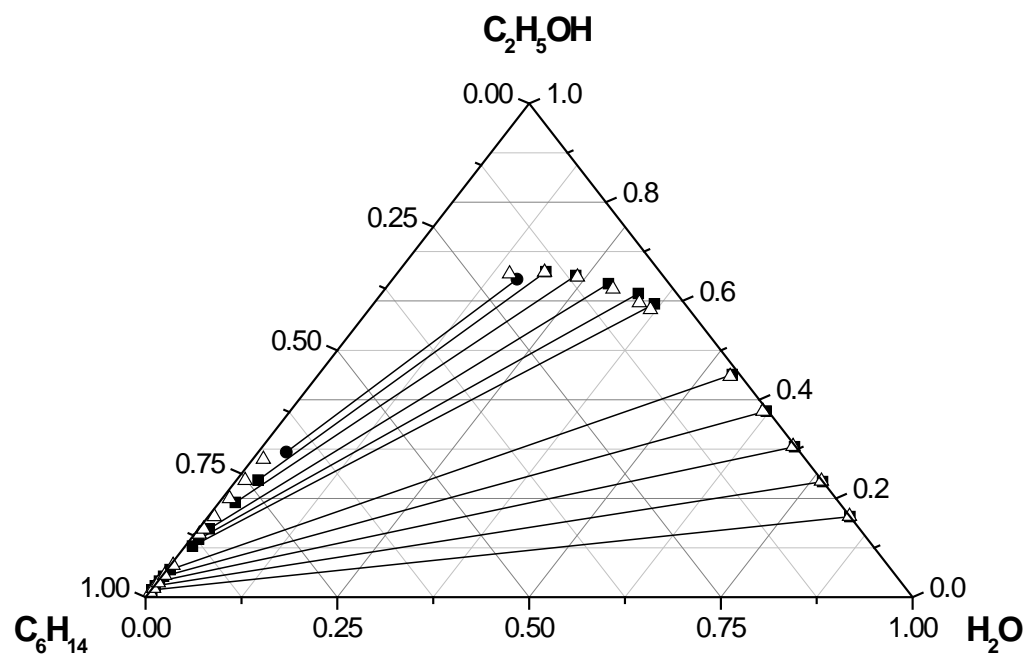

Fig. (5). LLE data of ethanol - water - hexane ternary mixture at $303.15 \mathrm{~K}$, 艦, experimental data; $\Delta$, by the UNIQUAC model.

\section{$\mathrm{C}_{2} \mathrm{H}_{5} \mathrm{OH}$}

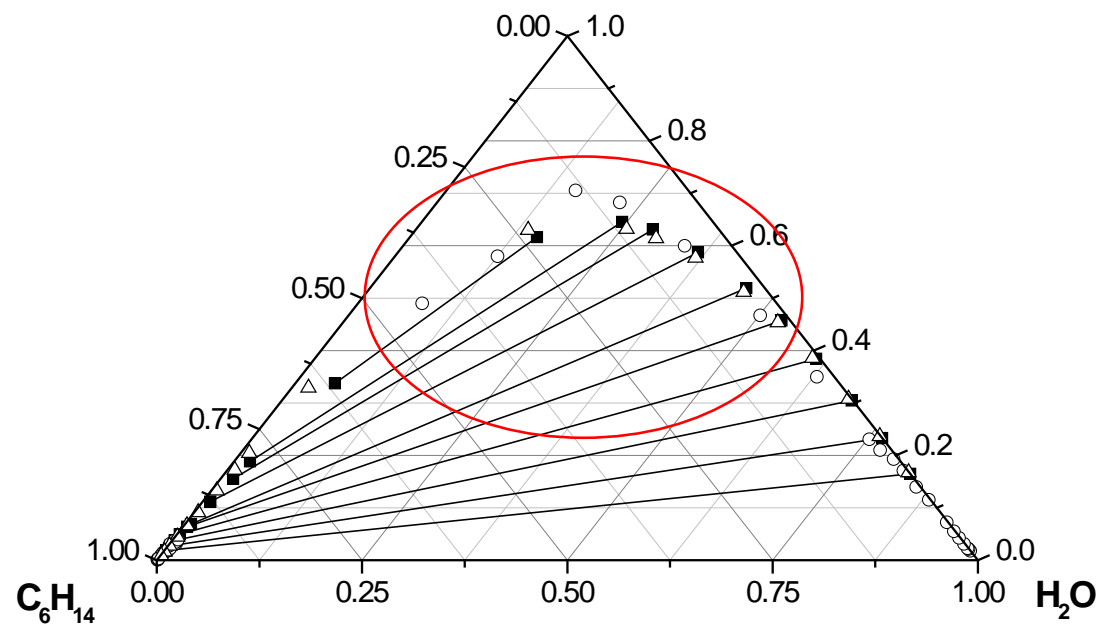

Fig. (6). LLE data of ethanol - water - hexane ternary mixture at $308.15 \mathrm{~K}$. UNIQUAC model. 


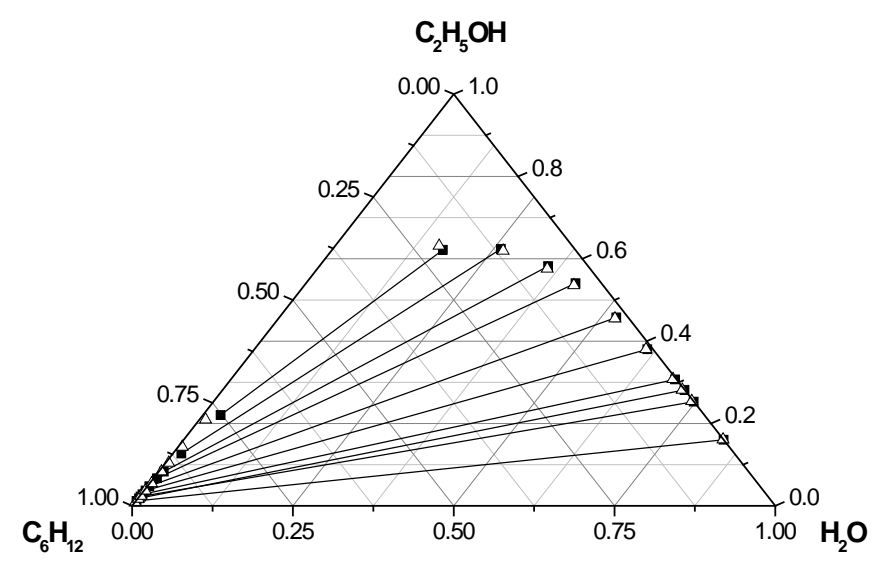

Fig. (7). LLE data of ethanol - water - cyclohexane ternary mixture at $303.15 \mathrm{~K}$.
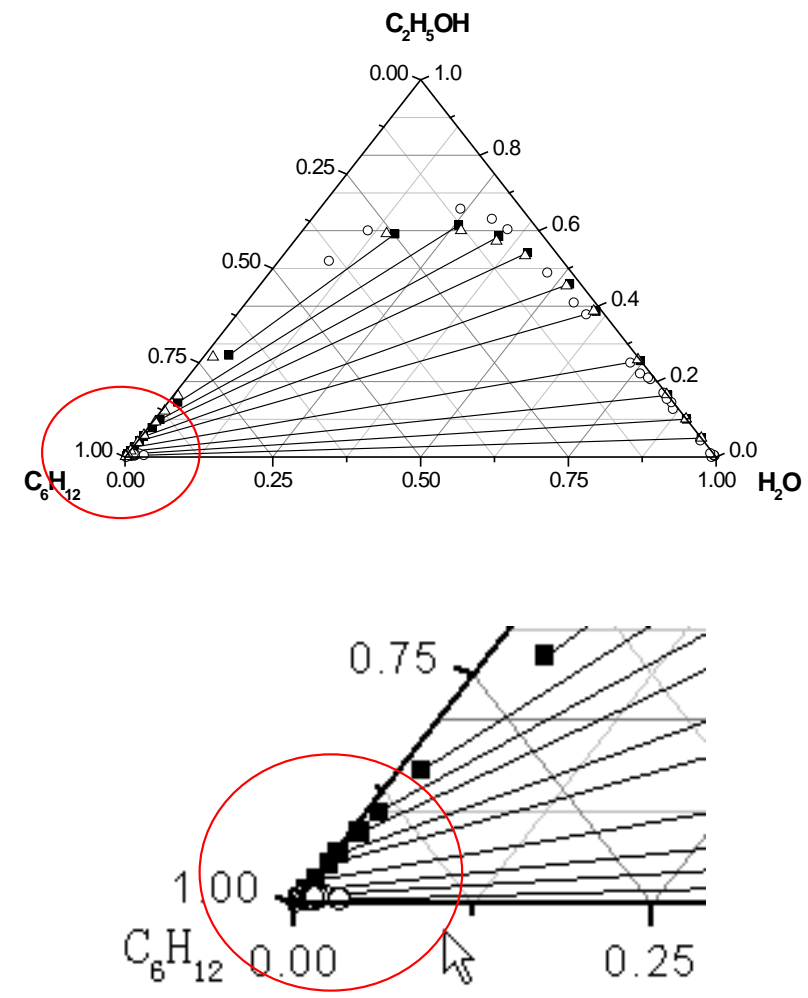

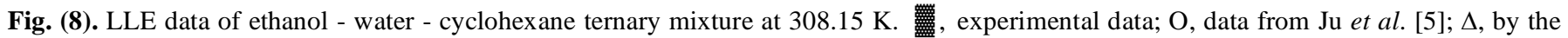
UNIQUAC model.

Table 5. The Correlation Parameters of the Uniquac Equation at 303.15 K of Ethanol-Water-Pentane, Ethanol-Water-Hexane, and Ethanol-Water-Cyclohexane Ternary Mixtures

\begin{tabular}{|c|c|c|}
\hline Binary Pair & Parameters, $\boldsymbol{a}_{i j}$ & Parameters, $\boldsymbol{a}_{j i}$ \\
\hline \hline ethanol-water & $-185.3^{\mathrm{a}}$ & $-167.38^{\mathrm{a}}$ \\
\hline ethanol-pentane & -57.876 & 338.474 \\
\hline ethanol-hexane & -70.283 & 482.824 \\
\hline ethanol-cyclohexane & -74.849 & $1340.7^{\mathrm{a}}$ \\
\hline water-pentane & $607.99^{\mathrm{a}}$ & 133 \\
\hline water-hexane & $572.51^{\mathrm{a}}$ & $1297.1^{\mathrm{a}}$ \\
\hline water-cyclohexane & $540.36^{\mathrm{a}}$ & $1247.3^{\mathrm{a}}$ \\
\hline
\end{tabular}

a from Aspen plus user's manual. 
Table 6. The Overall Deviations (RMSD) of Experimental and Calculated Data of Ternary Mixtures

\begin{tabular}{|c|c|c|c|c|c|}
\hline$\Delta x_{1}$ & $\Delta x_{2}$ & $\Delta x_{3}$ & $\Delta x_{1}$ & $\Delta x_{2}$ & $\Delta x_{3}$ \\
\hline \multicolumn{6}{|c|}{ Ethanol (1) + Water (2) + Pentane (3) } \\
\hline \multicolumn{6}{|c|}{$293.15 \mathrm{~K}$} \\
\hline \multicolumn{6}{|c|}{$303.15 \mathrm{~K}$} \\
\hline 0.0097 & 0.0096 & 0.0112 & 0.0218 & 0.0208 & 0.0036 \\
\hline \multicolumn{6}{|c|}{$308.15 \mathrm{~K}$} \\
\hline \multicolumn{6}{|c|}{ Ethanol (1) + Water (2) + Hexane (3) } \\
\hline \multicolumn{6}{|c|}{$293.15 \mathrm{~K}$} \\
\hline 0.0145 & 0.0094 & 0.0176 & 0.0117 & 0.0085 & 0.0063 \\
\hline \multicolumn{6}{|c|}{$303.15 \mathrm{~K}$} \\
\hline 0.0135 & 0.0094 & 0.0162 & 0.0082 & 0.0068 & 0.0048 \\
\hline \multicolumn{6}{|c|}{$308.15 \mathrm{~K}$} \\
\hline 0.0139 & 0.0096 & 0.0164 & 0.0092 & 0.0084 & 0.0047 \\
\hline \multicolumn{6}{|c|}{ Ethanol (1) + Water (2) + Cyclohexane (3) } \\
\hline \multicolumn{6}{|c|}{$303.15 \mathrm{~K}$} \\
\hline \multicolumn{6}{|c|}{$308.15 \mathrm{~K}$} \\
\hline 0.0113 & 0.0083 & 0.0131 & 0.0064 & 0.0063 & 0.0066 \\
\hline
\end{tabular}

The binary interaction parameters of the UNIQUAC model for this quinary mixture at $303.15 \mathrm{~K}$ were given in Table 13. And the correlated results in RMSD were listed in Table 14. Similar to quaternary mixtures, drawing a phase diagram of quinary mixture is not possible. However, the data of organic phase show that phase separation takes place at very low water concentration, i.e., the absorption of water moisture from air would easily cause phase separation and the loss of ethanol in the original gasohol. In order to have a better understanding phase behavior of organic and aqueous phases, two pseudo-three-component phase diagrams of ethanol + water + (pentane + hexane + cyclohexane) were drawn in Figs. 9 and 10, respectively for $303.15 \mathrm{~K}$ and $308.15 \mathrm{~K}$. These two figures show that the presence of water will cause phase separation at low concentration of ethanol.
In other words, the more ethanol added to gasohol would favor to maintain this mixture as a homogeneous phase and more efficient to consume ethanol as a fuel.

\section{CONCLUSION}

For environmental consideration, bio-product ethanol is added to gasoline as part of fuel. Unfortunately, ethanol will absorb water from air and possibly causes phase separation and the loss of ethanol as fuel by transferring from organic phase to aqueous phase. In order to understand phase behavior of mixture when ethanol is added to gasoline, the related mixtures of ethanol, water, pentane, hexane, and cyclohexane were investigated by experiment at temperatures of $283.15 \mathrm{~K}, 303.15 \mathrm{~K}$, and $308.15 \mathrm{~K}$. The mixtures include 
Table 7. Experimental LLE Data of the Ethanol (1) + Water (2) + Pentane (3) + Hexane (4) Quaternary Mixtures

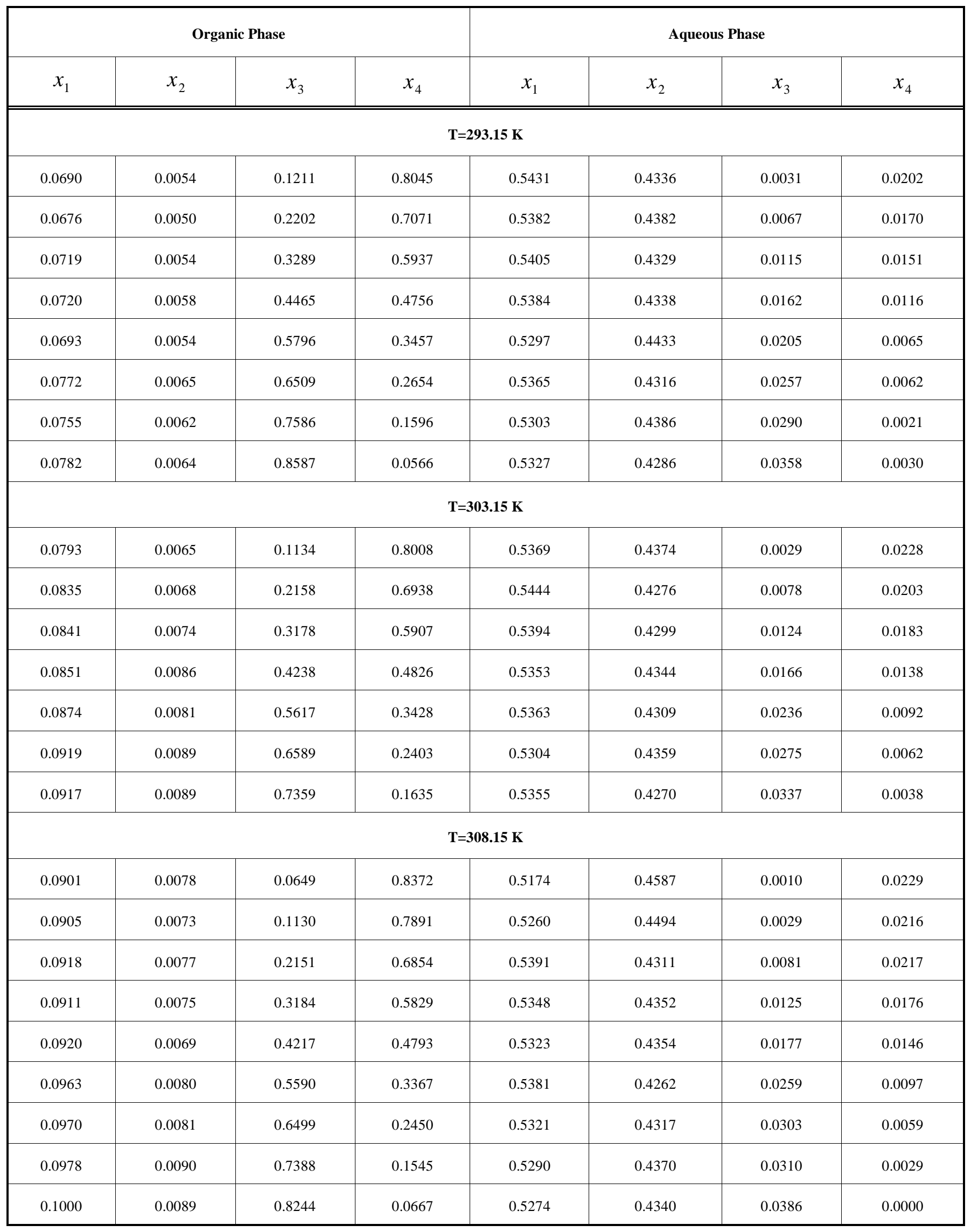


Table 8. Experimental LLE Data of Ethanol (1) + Water (2) + Pentane (3) + Cyclohexane (4) Quaternary Mixtures

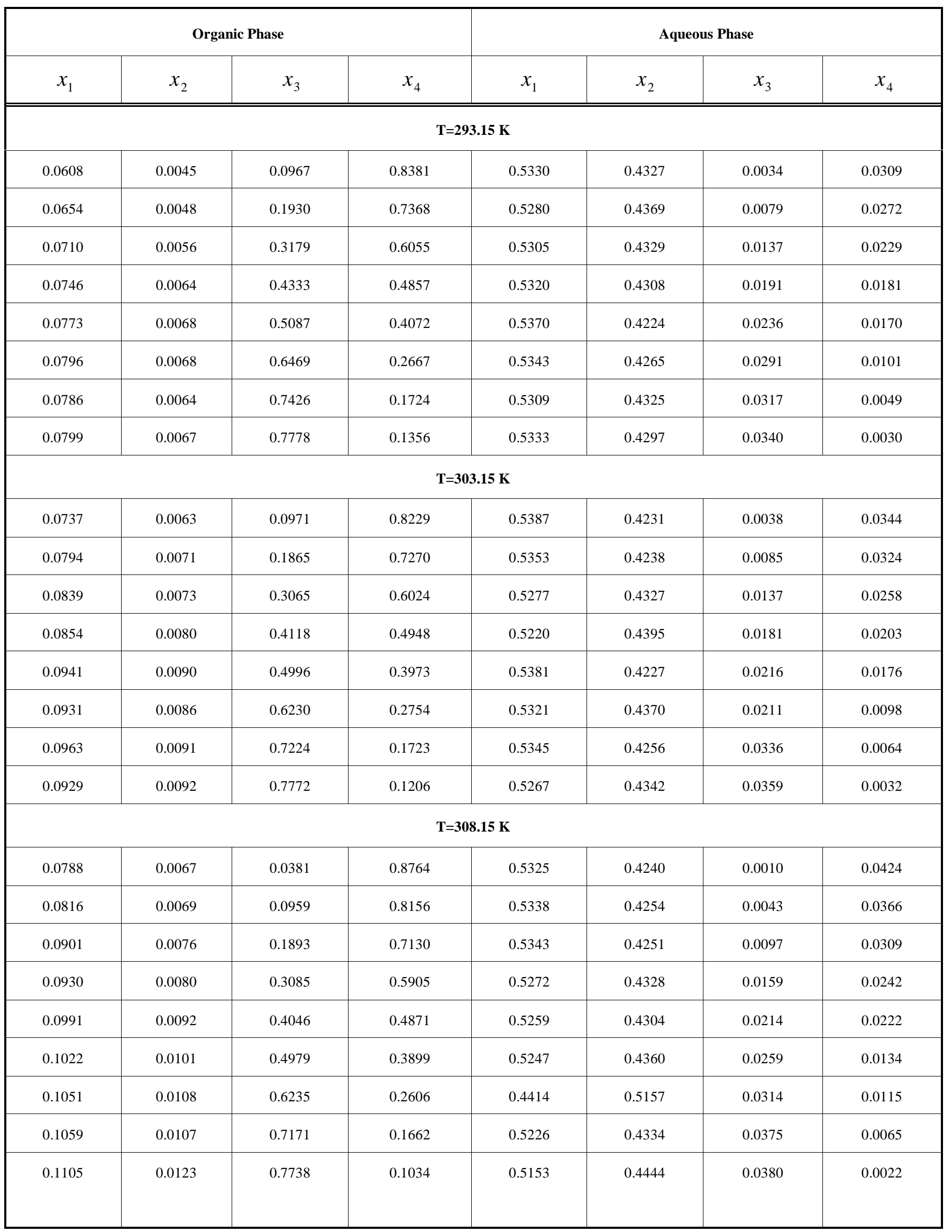


Table 9. Experimental LLE Data of the Ethanol (1) + Water (2) + Hexane (3) + Cyclohexane (4) Quaternary Mixtures

\begin{tabular}{|c|c|c|c|c|c|c|c|}
\hline \multicolumn{4}{|c|}{ Organic Phase } & \multicolumn{4}{|c|}{ Aqueous Phase } \\
\hline$x_{1}$ & $x_{2}$ & $x_{3}$ & $x_{4}$ & $x_{1}$ & $x_{2}$ & $x_{3}$ & $x_{4}$ \\
\hline \multicolumn{8}{|c|}{$T=293.15 \mathrm{~K}$} \\
\hline 0.0634 & 0.0042 & 0.1858 & 0.7466 & 0.5453 & 0.4239 & 0.0041 & 0.0267 \\
\hline 0.0638 & 0.0046 & 0.3016 & 0.6289 & 0.5412 & 0.4297 & 0.0075 & 0.0217 \\
\hline 0.0678 & 0.0048 & 0.3969 & 0.5305 & 0.5466 & 0.4245 & 0.0111 & 0.0179 \\
\hline 0.0665 & 0.0049 & 0.7446 & 0.1840 & 0.5395 & 0.4388 & 0.0181 & 0.0036 \\
\hline 0.0683 & 0.0050 & 0.8214 & 0.1053 & 0.5373 & 0.4419 & 0.0202 & 0.0007 \\
\hline \multicolumn{8}{|c|}{$T=303.15 \mathrm{~K}$} \\
\hline 0.0723 & 0.0063 & 0.0811 & 0.8403 & 0.5376 & 0.4264 & 0.0004 & 0.0356 \\
\hline 0.0759 & 0.0065 & 0.1781 & 0.7394 & 0.5380 & 0.4293 & 0.0041 & 0.0286 \\
\hline 0.0759 & 0.0065 & 0.2947 & 0.6228 & 0.5317 & 0.4374 & 0.0072 & 0.0237 \\
\hline 0.0797 & 0.0065 & 0.8063 & 0.1076 & 0.5362 & 0.4409 & 0.0218 & 0.0011 \\
\hline \multicolumn{8}{|c|}{$T=308.15 \mathrm{~K}$} \\
\hline 0.0794 & 0.0068 & 0.0350 & 0.8788 & 0.5351 & 0.4244 & 0.0000 & 0.0405 \\
\hline 0.0813 & 0.0071 & 0.0806 & 0.8310 & 0.5323 & 0.4289 & 0.0007 & 0.0381 \\
\hline 0.0838 & 0.0064 & 0.1767 & 0.7332 & 0.5350 & 0.4307 & 0.0042 & 0.0302 \\
\hline 0.0856 & 0.0066 & 0.3000 & 0.6077 & 0.5315 & 0.4391 & 0.0079 & 0.0214 \\
\hline 0.0902 & 0.0075 & 0.3907 & 0.5116 & 0.5367 & 0.4321 & 0.0118 & 0.0194 \\
\hline 0.0912 & 0.0072 & 0.4863 & 0.4153 & 0.5352 & 0.4305 & 0.0156 & 0.0188 \\
\hline 0.0897 & 0.0070 & 0.6241 & 0.2792 & 0.5365 & 0.4332 & 0.0199 & 0.0104 \\
\hline 0.0916 & 0.0074 & 0.7313 & 0.1697 & 0.5410 & 0.4316 & 0.0225 & 0.0049 \\
\hline 0.0939 & 0.0083 & 0.8029 & 0.0949 & 0.5395 & 0.4341 & 0.0248 & 0.0016 \\
\hline
\end{tabular}


Table 10. The Correlation Parameters of the Uniquac Equation for Quaternary Mixtures at 303.15 K

\begin{tabular}{|c|c|c|}
\hline \multicolumn{3}{|c|}{ Ethanol + Water + Pentane + Hexane } \\
\hline ethanol-water & 7.684 & 177.040 \\
\hline ethanol-pentane & -61.313 & 488.161 \\
\hline water-pentane & 1558.039 & 919.217 \\
\hline water-hexane & 328.948 & 1215.279 \\
\hline pentane-hexane & 255.519 & -198.450 \\
\hline ethanol-cyclohexane & 54.115 & 297.616 \\
\hline water-pentane & 43.052 & 1455.866 \\
\hline water-cyclohexane & 90.427 & 1122.772 \\
\hline pentane-cyclohexane & 176.837 & -159.226 \\
\hline \multicolumn{3}{|c|}{ Ethanol + Water + Hexane + Cyclohexane } \\
\hline ethanol-water & -496.834 & 88.497 \\
\hline
\end{tabular}

Table 11. The Over All Deviations (RMSD) of Experimental and Calculated Data of Quaternary Mixtures

\begin{tabular}{|c|c|c|c|c|c|c|c|}
\hline$\Delta x_{1}$ & $\Delta x_{2}$ & $\Delta x_{3}$ & $\Delta x_{4}$ & $\Delta x_{1}$ & $\Delta x_{2}$ & $\Delta x_{3}$ & $\Delta x_{4}$ \\
\hline \multicolumn{8}{|c|}{ Ethanol (1) + Water (2) + Pentane (3) + Hexane (4) } \\
\hline \multicolumn{8}{|c|}{$293.15 \mathrm{~K}$} \\
\hline \multicolumn{8}{|c|}{$303.15 \mathrm{~K}$} \\
\hline 0.0010 & 0.0003 & 0.0006 & 0.0008 & 0.0004 & 0.0003 & 0.0004 & 0.0006 \\
\hline \multicolumn{8}{|c|}{$308.15 \mathrm{~K}$} \\
\hline
\end{tabular}


Table 11. contd....

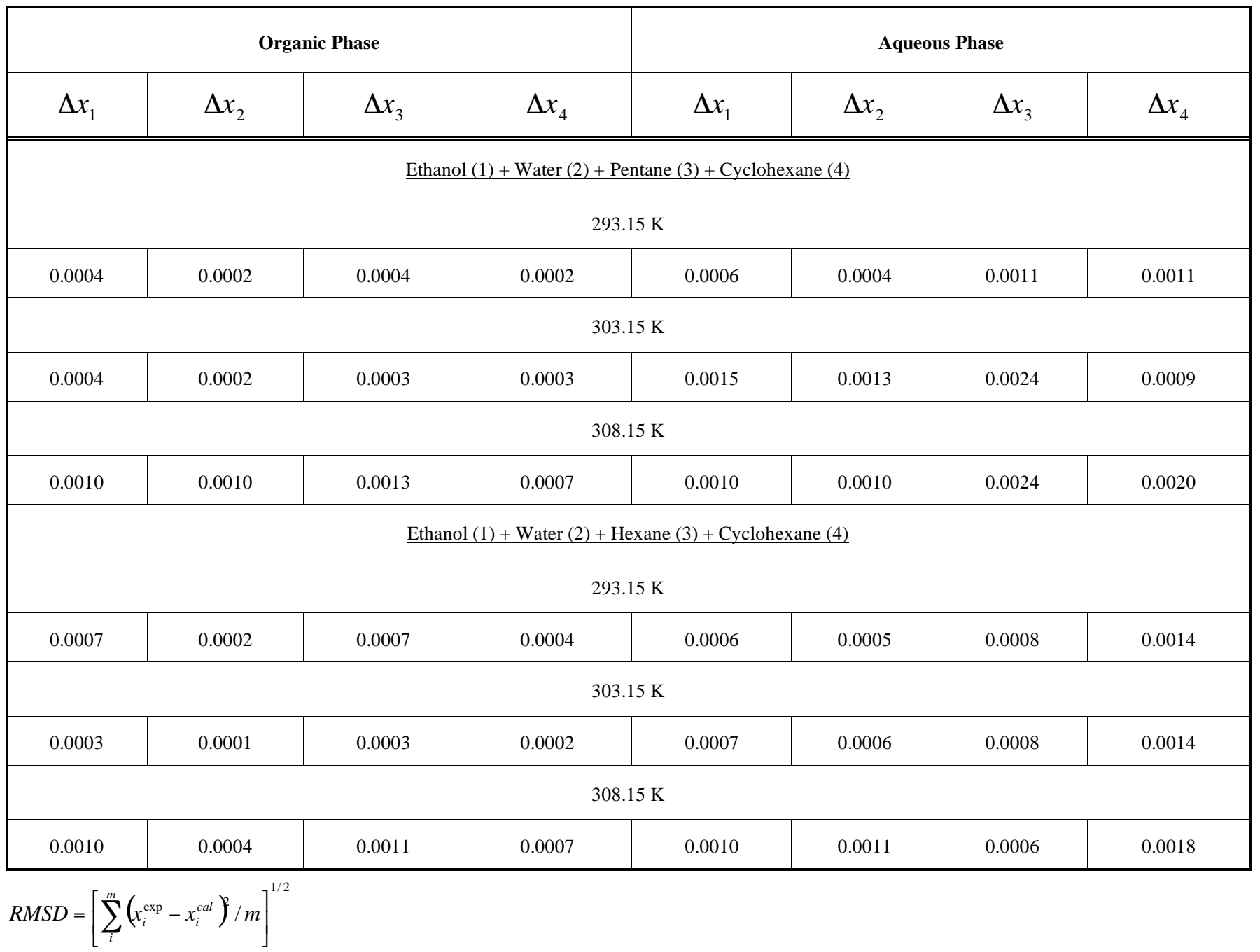

Table 12. Experimental LLE Data of Ethanol (1) + Water (2) + Pentane (3) + Hexane (4) + Cyclohexane (5) Quinary Mixtures

\begin{tabular}{|c|c|c|c|c|c|c|c|}
\hline \multicolumn{8}{|c|}{ 303.15 K } \\
\hline$x_{1}$ & $x_{2}$ & $x_{3}$ & $x_{4}$ & $x_{1}$ & $x_{2}$ & $x_{3}$ & $x_{4}$ \\
\hline 0.3515 & 0.0573 & 0.2628 & 0.2855 & 0.5771 & 0.1475 & 0.1240 & 0.1295 \\
\hline 0.1257 & 0.0117 & 0.3805 & 0.4172 & 0.5995 & 0.3320 & 0.0328 & 0.0301 \\
\hline 0.1106 & 0.0096 & 0.3904 & 0.4239 & 0.5795 & 0.3657 & 0.0264 & 0.0240 \\
\hline 0.0780 & 0.0063 & 0.4049 & 0.4424 & 0.5091 & 0.4642 & 0.0131 & 0.0118 \\
\hline 0.0617 & 0.0048 & 0.4176 & 0.4471 & 0.4461 & 0.5394 & 0.0071 & 0.0068 \\
\hline
\end{tabular}




\begin{tabular}{|c|c|c|c|c|c|c|c|}
\hline \multicolumn{4}{|c|}{ Organic Phase } & \multicolumn{4}{|c|}{ Aqueous Phase } \\
\hline \multicolumn{8}{|c|}{$308.15 \mathrm{~K}$} \\
\hline 0.3880 & 0.0682 & 0.2996 & 0.2084 & 0.5290 & 0.1232 & 0.1856 & 0.1352 \\
\hline 0.2403 & 0.0326 & 0.4012 & 0.2767 & 0.6191 & 0.2178 & 0.0856 & 0.0646 \\
\hline 0.1451 & 0.0146 & 0.4654 & 0.3167 & 0.6044 & 0.3167 & 0.0397 & 0.0327 \\
\hline 0.1165 & 0.0106 & 0.4827 & 0.3324 & 0.5697 & 0.3752 & 0.0276 & 0.0230 \\
\hline 0.0835 & 0.0064 & 0.5005 & 0.3455 & 0.5013 & 0.4712 & 0.0136 & 0.0118 \\
\hline 0.0749 & 0.0053 & 0.5076 & 0.3520 & 0.4758 & 0.5034 & 0.0100 & 0.0089 \\
\hline 0.0686 & 0.0051 & 0.5136 & 0.3538 & 0.4551 & 0.5277 & 0.0088 & 0.0075 \\
\hline 0.0652 & 0.0046 & 0.5109 & 0.3540 & 0.4391 & 0.5492 & 0.0048 & 0.0061 \\
\hline
\end{tabular}

Table 13. The Correlation Parameters of the Uniquac Equation of Quinary Mixture at 303.15 K

\begin{tabular}{|c|c|c|}
\hline Binary Pair & Parameters, $\boldsymbol{a}_{i j}$ & Parameters, $\boldsymbol{a}_{j i}$ \\
\hline \hline ethanol-water & -1.907 & -196.925 \\
\hline ethanol-pentane & -293.920 & 860.654 \\
\hline ethanol-hexane & -36.563 & 1307.729 \\
\hline ethanol-cyclohexane & -792.354 & 1455.866 \\
\hline water-pentane & 1817.775 & 1215.279 \\
\hline water-hexane & 1488.362 & 1122.772 \\
\hline water-cyclohexane & -1080.497 & -417.965 \\
\hline pentane-hexane & 1153.674 & -1106.867 \\
\hline pentane-cyclohexane & 1323.516 & 167.572 \\
\hline hexane-cyclohexane & -466.621 & \\
\hline
\end{tabular}

Table 14. The Overall Deviations (RMSD) of Experimental and Calculated Data of Ethanol (1) + Water(2) + Pentane (3) + Hexane (4) + Cyclohexane (5) Quinary System

\begin{tabular}{|c|c|c|c|c|c|c|c|c|c|}
\hline$\Delta x_{1}$ & $\Delta x_{2}$ & $\Delta x_{3}$ & $\Delta x_{4}$ & $\Delta x_{5}$ & $\Delta x_{1}$ & $\Delta x_{2}$ & $\Delta x_{3}$ & $\Delta x_{4}$ & $\Delta x_{5}$ \\
\hline \multicolumn{10}{|c|}{$303.15 \mathrm{~K}$} \\
\hline 0.0008 & 0.0028 & 0.0004 & 0.0013 & 0.0045 & 0.0006 & 0.0004 & 0.0009 & 0.0009 & 0.0011 \\
\hline 0.0007 & 0.0041 & 0.0007 & 0.0008 & 0.0041 & 0.0028 & 0.0008 & 0.0010 & 0.0008 & 0.0010 \\
\hline
\end{tabular}

$R M S D=\left[\sum_{i}^{m}\left(x_{i}^{\exp }-x_{i}^{c a l}\right)^{2} / m\right]^{1 / 2}$ 


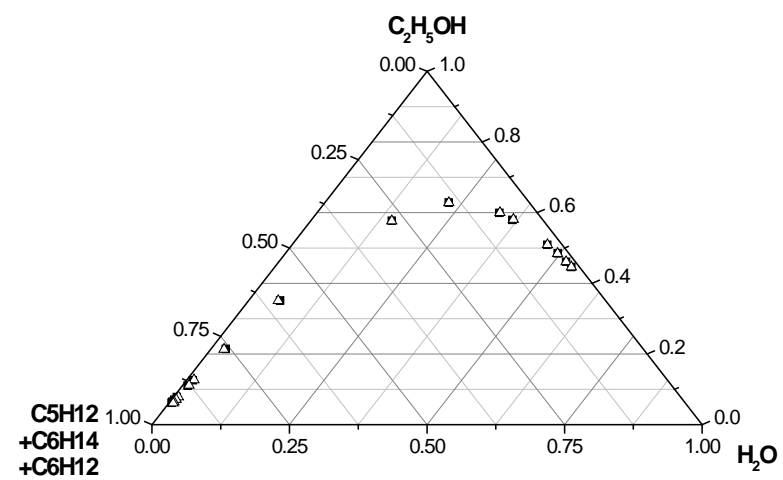

Fig. (9). Pseudo-three-component LLE diagram of ethanol-water-(pentane + hexane + cyclohexane) system at $303.15 \mathrm{~K}$.

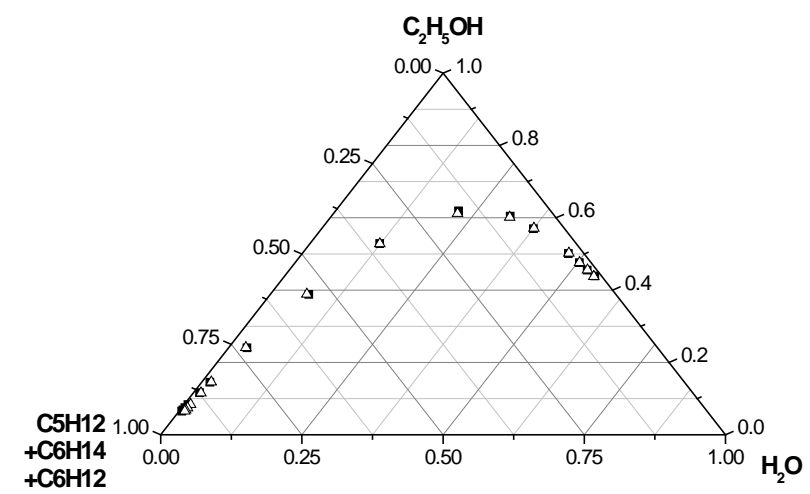

Fig. (10). Pseudo-three-component LLE diagram of ethanol-water-(pentane + hexane + cyclohexane) system at $308.15 \mathrm{~K}$.

three ternary of ethanol + water + pentane, ethanol + water + hexane, and ethanol + water + cyclohexane, three quaternary of ethanol + water + pentane + hexane, ethanol + water + pentane + cyclohexane, and ethanol + water + hexane + cyclohexane, and one quinary of all compounds listed above. The experimental data were reported and fairly correlated with the UNIQUAC model. The phase diagrams of ternary mixtures were also plotted with available literature data for comparison. In addition, the pseudo-phase diagrams of ethanol + water + (pentane + hexane + cyclohexane) at $303.15 \mathrm{~K}$ and $308.15 \mathrm{~K}$ were drawn.

The experimental data show that the solubility of water in organic phase is very small such that when moisture in air is absorbed into gasohol will easily cause phase separation and further transfer ethanol from organic phase to aqueous phase that is a loss of useful fuel. The way to avoid phase separation is preventing from contacting with air as possible as one can or increasing the ethanol concentration, i.e., adding more ethanol to gasoline. But there is a limitation of ethanol content in gasoline fuel attributed to the practical mechanical design of engine.

\section{REFERENCES}

[1] J. C. Galan, J. Sosa Cayero, A. M. Aguilar, and A. S. Segado, "Liquid-liquid equilibrium for the ethanol + water + pentane and ethanol + water + isopropyl nitrate systems," International Chemical Engineering, vol. 32, no. 3, pp. 531-537, 1992.

[2] L. Tang, and F. Liu, "Some Basic Properties of Hexane/alcohol mixture," Journal of Wuxi University of Light Industry, vol. 15, pp. 313-317, 1996.

[3] H. Xu, H. F. Ju, W. Wang, and J. Huang, "Research on the liquidliquid equilibrium in system water- n-hexane-ethanol system," Chemical Research and Application, vol. 18, pp. 409-412, 2006.

[4] S. Ross, and R. Patterson, "Surface and interfacial tensions of conjugate solutions n ternary system," Journal of Chemical and Engineering Data, vol. 24, pp. 111-115, 1979.

[5] H. F. Ju, H. Xu, Y. F. Shao, andf W. Y. Ying, "liquid-liquid equilibrium of the water- cyclohexane system," Journal of Chemical Engineering of Chinese University, vol. 20, pp. 643-647, 2006,

[6] M. B. Gramajo de Doz, C. M. Bonatti, and H. N. Sólimo, "(liquid + liquid) equilibria of ternary and quaternary systems with two hydrocarbons, an alcohol, and water at $313.15 \mathrm{~K}$ systems containing cyclophexane, benzene, ethanol, and water," The Journal of Chemical Thermodynamics, vol. 35, pp. 2055-2065, 2003.

[7] M. B. Gramajo de Doz, C. M. Bonatti, and H. N. Sólimo, "liquidliquid equilibrium of water + ethanol + reformate," Fluid Phase Equilibria, vol. 230, pp. 45-50, 2005.

[8] T. Moriyoshi, Y. Uosaki, H. Matsuura, and W. Nishimoto, "(Liquid + liquid) equilibria of (water + ethanol + n-hexane) from 0.1 to 200 MPa at $298.15 \mathrm{~K}$," The Journal of Chemical Thermodynamics, vol. 20, pp. 551-557, 1988.

[9] L. S. Lee, and H. Y. Huang, "Liquid-liquid equilibrium behavior of tetrabutylammonium bromide, benzene, and water mixture," Fluid Phase Equilibria, vol. 205, pp. 133-147, 2003. 